\title{
STUDY OF GLASS FORMING ABILITY PARAMETERS OF Mg-Ni-Pr-BASED METALLIC GLASSES
}

\author{
SONAL R. PRAJAPATI \\ Condensed Matter Physics Laboratory, Applied Physics Department, \\ Faculty of Technology and Engineering, The M.S.University of Baroda \\ Vadodara, Gujarat-390001, India \\ sonal051987@yahoo.in \\ ASHMI T. PATEL \\ Condensed Matter Physics Laboratory, Applied Physics Department, \\ Faculty of Technology and Engineering, The M.S.University of Baroda \\ Vadodara, Gujarat-390001, India \\ ashmi0707@yahoo.co.in \\ ARUN PRATAP \\ Condensed Matter Physics Laboratory, Applied Physics Department, \\ Faculty of Technology and Engineering, The M.S.University of Baroda \\ Vadodara, Gujarat-390001, India \\ apratapmsu@yahoo.com
}

\begin{abstract}
Knowledge of Glass forming Ability (GFA) of metallic glasses is of great importance as it gives an insight of a better Glass former. Number of GFA parameters like Gibb's free energy difference $\Delta \mathrm{G}, \Delta \mathrm{S}, \Delta \mathrm{H}, \eta, \gamma, \gamma_{\mathrm{m}}, \mathrm{Q}, \mathrm{T}_{\mathrm{rg}}\left(=\mathrm{T}_{\mathrm{g}} / \mathrm{T}_{1}\right)$ etc. are calculated and compared for Mg-Ni-Pr-based metallic glass forming alloys to predict which parameter describes the best GFA criterion. On the basis of these parameters the excellent glass forming composition is identified. Also the GFA parameters of Mg-Ni-Pr-based alloys are studied in air and argon atmosphere. Present work suggests that $\Delta \mathrm{G}$ is the best GFA criterion and Mg-Ni-Pr-based metallic glassy alloys can be successfully fabricated in air due to its high oxidation resistance ability.
\end{abstract}

Keywords: Bulk Metallic Glasses, Gibb's Free Energy, GFA.

\section{Introduction}

Bulk metallic glasses have found significant interest in research as it has many applications. Various parameters and criteria have been proposed to predict GFA. Glass formation is a competition process between super-cooled liquid and the related crystalline phases. ${ }^{1}$ In order to find better glass forming metallic glass many theoretical approaches have been put forward through criteria like reduced glass transition temperature $\left(T_{r g}\right)$, order parameter $(\eta)$, parameters $Q, \gamma, \gamma_{m}$, and the Gibb's Free energy difference $(\Delta G)$ between the super-cooled liquid and crystalline phases. A large number of systems follow these all criteria with some exceptions. The driving force of nucleation is given by 
thermodynamic factor i.e. Gibb's free energy difference $\Delta G$. Lower the value of $\Delta G$ lesser will be the driving force of nucleation which degrades the crystallization hence better will be the GFA. ${ }^{2}$

In the present work different GFA criteria for Mg-Based metallic alloys with different composition and in different atmosphere are calculated. The thermodynamic properties like $\Delta G$ and $\Delta S$ are also determined.

\section{Formulation of Theoretical Expression}

The Gibbs free energy difference gives a qualitative measure of the stability of the glass compared to the crystalline state. The difference in Gibbs free energy between the liquid and crystalline phases is given by

$$
\Delta G=\Delta H-T \Delta S .
$$

Where,

$$
\Delta H=\Delta H_{m}-\int_{T}^{T_{m}} \Delta C_{p} d T .
$$

And

$$
\Delta S=\Delta S_{m}-\int_{T}^{T_{m}} \Delta C_{p} \frac{d T}{T}
$$

Where, $T_{m}$ is the melting temperature, $\Delta S_{m}$ is the entropy of fusion and $\Delta H_{m}$ is the enthalpy of fusion. They are related to each other by the following relation:

$$
\Delta S_{m}=\frac{\Delta H_{m}}{T_{m}} .
$$

$\Delta \mathrm{C}_{\mathrm{p}}$, defined as $\mathrm{C}_{\mathrm{p}}{ }^{1}-\mathrm{C}_{\mathrm{p}}{ }^{\mathrm{x}}$, is the difference in specific heat of liquid and the corresponding crystalline phases of metallic alloy. The most common linear expression is given by

$$
\Delta C_{p}=A T+B
$$

Substituting Eq. (5) in Eqs. (2) and (3), Eq. (1) can be simplified to

$$
\Delta G=\frac{\Delta H_{m} \Delta T}{T_{m}}-\frac{1}{2} A(\Delta T)^{2}+B\left(T \ln \frac{T_{m}}{T}-\Delta T\right) .
$$

Considering large undercooled region of the multicomponent metallic alloys Lad et al. ${ }^{3}$ obtained the following expression.

$$
\Delta G=\frac{\Delta H_{m} \Delta T}{T_{m}}\left(1-\frac{\Delta T}{2 T}\right) .
$$

Considering logarithmic term in eq. (6) and taking the Taylor series expansion up to second order gives the following approximation:

$$
\ln \left(\frac{T_{m}}{T}\right) \cong \frac{4 T \Delta T}{\left(T+T_{m}\right)^{2}} .
$$


Substituting Eq. (8) in Eq. (6) Lad et al. ${ }^{4}$ obtained the following equation for the Gibb's free energy difference

$$
\Delta G=\frac{\Delta H_{m} \Delta T}{T_{m}}\left(\frac{4 T^{2}}{\left(T+T_{m}\right)^{2}}\right) .
$$

The entropy difference can be obtained by taking partial derivative of $\Delta G$ w.r.t to t:

$$
\Delta S=-\frac{\partial(\Delta G)}{\partial T} .
$$

Substituting Eq. (7) \& (9) in (10) we get the following equation,

$$
\begin{aligned}
& \Delta S_{1}=\frac{\Delta H_{m}}{2 T_{m}}\left(\frac{3 T^{2}-T_{m}^{2}}{T^{2}}\right) . \\
& \Delta S_{2}=\frac{4 \Delta H_{m} T}{T_{m}}\left(\frac{T^{2}-2 T_{m}^{2}+3 T T_{m}}{\left(T+T_{m}\right)^{3}}\right) .
\end{aligned}
$$

\section{Results and Discussion}

Many criteria have been predicted for finding the GFA of metallic glasses like $\gamma_{m}\left(=2 T_{x^{-}}\right.$ $\left.T_{g} / T_{l}\right), Q\left(=\left(T_{g}+T_{x}\right) / T_{l}\right), \eta\left(=1-\Delta H_{x} / \Delta H_{m}\right), \gamma\left(=T_{x} /\left(T_{g}+T_{l}\right)\right), T_{r g}\left(=T_{g} / T_{l}\right)$ etc. where, $T_{l}, T_{x}, T_{g}$ are liquidus, crystallization, and glass transition temperature respectively. All parameters are calculated in Table-1 which shows that $\mathrm{T}_{\mathrm{rg}}, \gamma, \gamma_{m}$ gives constant value which cannot give idea about variation in GFA for the given compositions. One can see that there is a significant variation in $\Delta G$ values which can predict better glass forming composition.

\begin{tabular}{|c|c|c|c|c|c|c|c|c|c|c|c|c|}
\hline Systems. ${ }^{5}$ & $\begin{array}{c}\Delta T x \\
(\mathrm{~K}) .^{5}\end{array}$ & $Q$ & $T_{r g}{ }^{5}$ & $\eta$ & $\gamma^{5}$ & $\gamma_{m}$ & $\begin{array}{c}\Delta G_{l}\left(T_{g}\right) \\
(\mathrm{Lad}-1) \\
\mathrm{kJ} / \mathrm{mol}\end{array}$ & $\begin{array}{c}\Delta G_{2}\left(T_{g}\right) \\
(\mathrm{Lad}-2) \\
\mathrm{kJ} / \mathrm{mol}\end{array}$ & $\begin{array}{c}\Delta G_{l}\left(T_{g}\right) \\
\quad \Delta H_{m}\end{array}$ & $\begin{array}{c}\Delta G_{2}\left(T_{g}\right) \\
/ \Delta H_{m}\end{array}$ & $\begin{array}{l}\Delta S_{l}\left(T_{g}\right) \\
(\text { Lad-1) } \\
\mathrm{kJ} / \mathrm{mol}\end{array}$ & $\begin{array}{c}\Delta S_{2}\left(T_{g}\right) \\
(\mathrm{Lad}-2) \\
\mathrm{kJ} / \mathrm{mol}\end{array}$ \\
\hline $\mathrm{Mg}_{48} \mathrm{Ni}_{31} \mathrm{Pr}_{21}$ & 47 & 0.451 & 0.570 & 0.627 & 0.403 & 0.695 & 2.92 & 2.47 & 0.265 & 0.249 & 1.77 & 1.45 \\
\hline $\mathrm{Mg}_{63} \mathrm{Ni}_{22} \mathrm{Pr}_{15}$ & 52 & 0.803 & 0.574 & 0.339 & 0.407 & 0.708 & 1.35 & 1.14 & 0.265 & 0.224 & 0.53 & 0.51 \\
\hline $\mathrm{Mg}_{65} \mathrm{Ni}_{21} \mathrm{Pr}_{14}$ & 42 & 0.907 & 0.569 & 0.238 & 0.396 & 0.675 & 1.38 & 1.17 & 0.264 & 0.224 & 0.91 & 0.72 \\
\hline $\begin{array}{l}\mathrm{Mg}_{65} \mathrm{Ni}_{21} \mathrm{Pr}_{14} \\
\text { (air) }\end{array}$ & 41 & 0.814 & 0.574 & 0.322 & 0.397 & 0.678 & 1.50 & 1.26 & 0.265 & 0.223 & 0.93 & 0.75 \\
\hline
\end{tabular}
$\Delta \mathrm{G}$ is the driving force for crystallization. Lower the value of $\Delta \mathrm{G}$, higher is the GFA of metallic alloys.

Table 1. Different GFA Criteria

$\Delta G$ is calculated for the entire undercooled region, from Lad-1 \&Lad-2 equations. Figure -1 shows $\Delta G$ variation with temperature for $\mathrm{Mg}_{48} \mathrm{Ni}_{31} \mathrm{Pr}_{21}$ and $\mathrm{Mg}_{63} \mathrm{Ni}_{22} \mathrm{Pr}_{15}$ metallic glasses. Lower the value of $\Delta G\left(T_{g}\right)$ indicates better GFA and hence $\mathrm{Mg}_{63} \mathrm{Ni}_{22} \mathrm{Pr}_{15}$ is better glass former. 


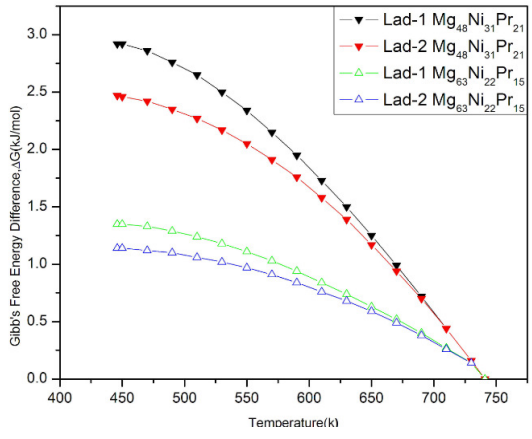

Figure 1. Gibb's free energy difference with Temperature for $\mathrm{Mg}_{48} \mathrm{Ni}_{31} \mathrm{Pr}_{21}$ and $\mathrm{Mg}_{63} \mathrm{Ni}_{22} \mathrm{Pr}_{15}$

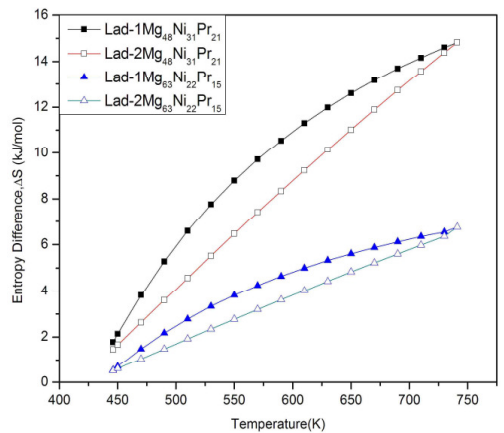

Figure 3. Entropy Difference with Temperature for $\mathrm{Mg}_{63} \mathrm{Ni}_{22} \mathrm{Pr}_{15}$ and $\mathrm{Mg}_{48} \mathrm{Ni}_{31} \mathrm{Pr}_{21}$.

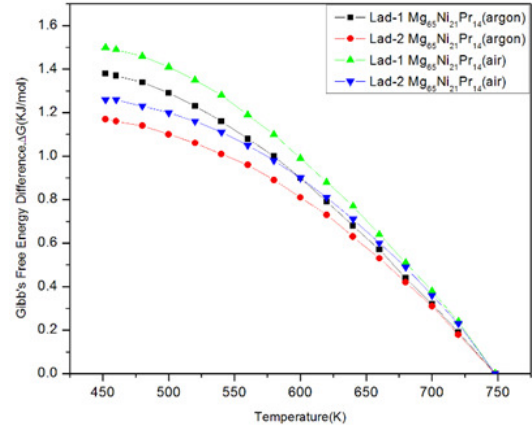

Figure 2. Gibb's free energy difference with Temperature for $\mathrm{Mg}_{65} \mathrm{Ni}_{21} \mathrm{Pr}_{14}$ in air and argon atmosphere.

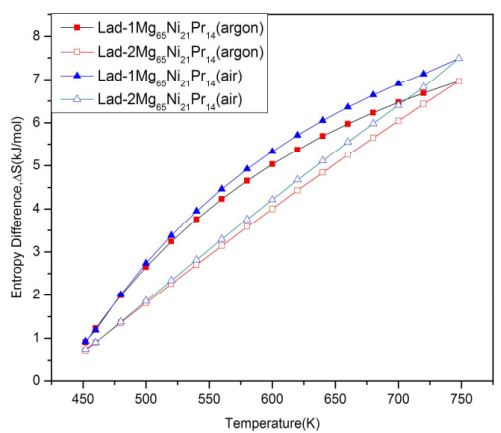

Figure 4. Entropy Difference with Temperature for $\mathrm{Mg}_{65} \mathrm{Ni}_{21} \mathrm{Pr}_{14}$ in air and argon atmosphere.

Lower value of $\Delta G\left(T_{g}\right)$ indicates higher GFA and hence $\mathrm{Mg}_{63} \mathrm{Ni}_{22} \mathrm{Pr}_{15}$ is better glass former. Lad-2 gives smaller value of $\Delta G\left(T_{g}\right)$ than Lad-1 for both the systems as given in table-1 which indicates that it is good approximation. $\mathrm{Mg}_{65} \mathrm{Ni}_{21} \mathrm{Pr}_{14}$ metallic glass produced in argon is better glass former than $\mathrm{Mg}_{65} \mathrm{Ni}_{21} \mathrm{Pr}_{14}$ produced in air as $\Delta G\left(T_{g}\right)$ is lower for sample prepared in argon as shown in figure-2. Mg-Ni-Pr system has high oxidation resistance ability so it can be prepared in air but for other BMGs it is not possible as in air they favour crystallization. The entropy difference, $\Delta \mathrm{S}$, between the undercooled liquid and the corresponding crystalline phase has also been calculated from Eq. (11) \&(12), and plotted in fig. (3) \& (4), for all the four composition i.e. $\mathrm{Mg}_{48} \mathrm{Ni}_{31} \mathrm{Pr}_{21}, \mathrm{Mg}_{63} \mathrm{Ni}_{22} \mathrm{Pr}_{15}, \mathrm{Mg}_{65} \mathrm{Ni}_{21} \mathrm{Pr}_{14}, \mathrm{Mg}_{65} \mathrm{Ni}_{21} \mathrm{Pr}_{14}$ (air).

\section{Conclusion}

It can be concluded that $\mathrm{Mg}_{63} \mathrm{Ni}_{22} \mathrm{Pr}_{15}$ is the best glass former among all composition as the driving force of crystallization; $\Delta G$ is very low for it which indicates excellent GFA. 
$\mathrm{Mg}_{65} \mathrm{Ni}_{21} \mathrm{Pr}_{14}$ though has better GFA in argon atmosphere, but it can also be successfully prepared in air which is not possible for synthesis of other BMG's. $\Delta G$ value for $\mathrm{Mg}_{65} \mathrm{Ni}_{21} \mathrm{Pr}_{14}$ metallic glass which is prepared in air has comparatively smaller value of $\Delta G\left(T_{g}\right)$ which indicates that $\mathrm{Mg}_{65} \mathrm{Ni}_{21} \mathrm{Pr}_{14}$ is also a good glass former.

\section{References}

1. Z.Y.Suo, K.Q.Qui, Q.F.Li, J.H.You, Y.L.Ren, Z.Q.Hu, Mater. Science \& Engg. A, 528(2010), 429-433

2. A.T.Patel, K.N.Lad, Arun Pratap, Solid State Phen.,171(2011),121-126

3. K.N.Lad,Arun Pratap,K.G.Raval, J.Mater. Science Lett.,21(2002), 1419-1422

4. K.N.Lad, K.G.Raval, Arun Pratap, J.Non-Cryst. Solid, 334\&335(2004), 259-262

5. Y.X.Wei, X.K.Xi, D.Q.Zhao, M.X.Pan, W.H.Wang, Mater.Lett. 59 (2005), pp. 945-974 